Artículos

\title{
Trajetória de redes: uma análise da dinâmica da agência e relacionamentos numa rede de produtores rurais de bovinos de corte
}

Network pathway: an analysis of agency dynamics and relationships in cattle rural producers network

Marcelo Fernandes Pacheco Dias

DOI: https://doi.org/10.24215/15155994e146

Departamento de Ciências Sociais Agrárias - Faculdade de Redalyc: http://www.redalyc.org/articulo.oa?id=84563515008 Agronomia Eliseu Maciel, Universidade Federal de Pelotas,

Brasil

marcelo.dias@ufpel.edu.br

Cynthia Pires Hartwig

Departamento de Ciências Sociais Agrárias - Faculdade de

Agronomia Eliseu Maciel, Universidade Federal de Pelotas,

Brasil

cynthiagallopires@gmail.com

Recepción: 01 Abril 2019

Aprobación: 27 Diciembre 2019

\section{Resumo:}

Este artigo tem por objetivo analisar a trajetória da agência e das mudanças nos relacionamentos entre os atores numa rede de produtores rurais que vem até o momento obtendo sucesso na sua organização. $\mathrm{O}$ estudo de caso foi realizado numa rede de produtores de gado de corte denominada Associação dos Produtores dos Campos de Cima da Serra do Estado do Rio Grande do Sul no Brasil - APROCCIMA. Foram utilizadas duas estratégias metodológicas, uma qualitativa e outra quantitativa. Como resultados, foram observados dois tipos de agência: Partner mode e Intermediary mode e seis eventos na rede estudada. A partir dos eventos foi observada uma melhora na estrutura da rede em quatro das cinco características de relacionamentos. Constatou-se centralidade decrescente, cliques maiores, densidade crescente, grau de assortatividade decrescente e crescente número de atores participando do núcleo central da rede.

Palavras-Chave: Redes Flexíveis, Eventos, Análise de Redes Sociais, Bovinos de Corte.

\section{Abstract:}

This article aims to analyze the trajectory of the agency and relationship changes between actors in a rural producer's network that has been successful in the organization so far. The case study was carried out at Producers Association from Mountain Top Fields in the state of Rio Grande do Sul in Brazil - APROCCIMA in the State of Rio Grande do Sul. Two methodological strategies were used, one qualitative and the other quantitative. Two types of agency were observed: Partner mode and Intermediary mode, and six events in the studied network. From the events, an improvement in the structure of the network was observed in four of the five characteristics of relationships. It was found decreasing centrality, larger clicks, increasing density, decreasing assortment rate and increasing number of actors participating in the central nucleus of the network.

KEYWORDS: Flexible Networks, Events, Social Network Analysis, Cattle.

\section{ITRODUÇÃo}

Os agentes da cadeia da carne estão constantemente enfrentando pressões por maior competitividade e aumento da produtividade (Barcellos, Barella, Peretti \& Galleli, 2015). Apesar do desafio de se manterem competitivos através da produtividade, novos desafios têm sido adicionados a estes agentes, como as demandas da sociedade por práticas produtivas, de industrialização e de comercialização que sejam socialmente justas, ambientalmente sustentáveis e economicamente viáveis (Barcellos et al., 2015). Por isso, os agentes desta cadeia têm sido incentivados ao desenvolvimento da pecuária orgânica no Brasil, tanto pela 
demanda interna quanto externa para a carne produzida dessa forma, apesar da carência de pesquisa, de ensino, de divulgação e de profissionais habilitados (Escosteguy, 2016). Além das exigências por parte da demanda, os agentes da cadeia da carne precisam cumprir as determinações da legislação vigente quanto ao uso do solo, água, tratamento de resíduos, conservação da fauna e flora nativas, etc. (Barcellos et al., 2015).

Diante das dificuldades e desafios que se impõem ao setor da carne bovina, pecuaristas, abatedourosfrigoríficos, distribuidores e varejistas, motivados pela manutenção e sobrevivência de seus empreendimentos em um mercado competitivo e de fronteiras expandidas, estão adotando, cada vez mais, a formação de arranjos em forma de redes, pois, conforme citam Agranoff e Mcguire (2001), as organizações formam redes para resolverem problemas que sozinhas não conseguiriam resolver.

As redes são definidas como grupos de organizações com interesses comuns, que se unem para a melhoria da competitividade a partir da prática da cooperação. Esse conceito é aplicado a diferentes configurações interorganizacionais, como joint ventures, alianças estratégicas, relações de terceirização e subcontratação, distritos industriais, redes sociais e flexíveis (Braga, 2010; Cropper, Ebers, Huxham \& Ring, 2014). Esses novos modelos organizacionais, mais horizontalizados e menos hierarquizados, são necessários para que todos os agentes envolvidos sejam beneficiados no sentido de conquistarem maior participação no mercado que já atuam e, até mesmo, atingirem novos (Feldhaus, Pereira \& Morais Neto, 2012).

Entretanto, as redes relativas ao setor produtivo da carne ainda são poucas no Brasil, muitas delas em formação como é o caso da Alianza del Pastizal. Nos poucos casos existentes (Oliveira, Gianezini, Peripoli, \& Barcellos, 2015), observa-se que elas enfrentam barreiras para se consolidarem. Ferreira e Padula (2002) citam que uma das principais barreiras à formação das redes tem origem na resistência dos parceiros em estabelecerem negociações mais estáveis e formalizadas, por exemplo, contratos de fornecimento. Somase a isso a existência de uma fraca coordenação entre os atores do setor da carne bovina (produtores, frigoríficos e varejistas), o que tem como consequências negativas, além da resistência à formalização de compromissos, a dificuldade para o compartilhamento de informações, a falta de confiança entre os agentes e o comportamento oportunista (Pereira, Venturini, Wegner, \& Braga, 2010; Wegner \& Padula, 2010).

A Rede de Produtores organizada formalmente na Associação dos Produtores dos Campos de Cima da Serra - APROCCIMA tem se caracterizado como uma exceção. Esta é uma associação de produtores de gado fundada em maio de 2006. Sua origem remonta ao ano de 1997, a partir da organização conjunta e voluntária de 16 produtores rurais que constituíam o CITE 120. A Aliança Mercadológica APROCCIMA se define como uma aliança mercadológica de iniciativa dos produtores rurais que coordenam o sistema de produção, o padrão de qualidade e o preço de comercialização dos animais, além de coordenar o processamento e comercialização da carne produzida pelos seus membros (APROCCIMA, 2018).

Os poucos casos de redes relativas ao setor produtivo da carne bovina e as dificuldades que estas organizações enfrentam remete a necessidade de melhor compreensão sobre como estas organizações são formadas e evoluem ao longo do tempo. Ao se analisar os estudos sobre como as redes se formam e evoluem, estes têm sido associados a eventos externos na desestabilização das lógicas existentes entre os atores de um determinado setor e assim favorecem o início e a manutenção da interação (Halinen \& Törnroos, 2013; Corbo, Corrado \& Ferriani, 2016; Dagnino, Levanti \& Destri, 2016; Agostino, Arnaboldi, \& Dal Molin, 2017).

Esta ênfase em eventos externos na formação e evolução de redes interorganizacionais tem sido criticada e demanda por mais pesquisas sobre a contribuição de eventos com origem na agência individual e coletiva para a explicação do fenômeno de formação e evolução das redes (Ahuja, Soda, \& Zaheer, 2012; Musiolik, Markard, Hekkert, \& Furrer, 2018). Além disso, independentemente da origem destes eventos, tais resultados dizem pouco sobre quais lógicas de relacionamentos moldam a trajetória evolutiva nas redes. Abordar essa lacuna do conhecimento é importante para o avanço do entendimento atual da dinâmica das redes no que concerne às relações particulares entre seus atores (Ahuja et al., 2012; Corbo et al., 2016). 
A Teoria dos Eventos pode contribuir para a melhor compreensão dos eventos com origem na agência individual e coletiva, pois considera que processos de mudança podem ser causados por forças internas e/ou externas à rede (Hedaa \& Törnroos, 2008). Na Teoria dos Eventos as redes são estáveis ao mesmo tempo em que mudam constantemente, pois através de adaptações contínuas mudam para não desaparecerem (Hedaa \& Törnroos, 2008). Logo, eventos são definidos como o resultado de uma ação humana individual ou coletiva, e de acontecimentos externos como os relativos aos fenômenos da natureza (Hedaa \& Törnroos, 2008). Se a Teoria dos Eventos dá um indicativo das origens dos eventos e de quando eles ocorrem, a Teoria da Análise de Redes Sociais (Wasserman \& Faust, 1984) pode contribuir com indicadores estruturais sobre como as relações mudam e delineiam novas configurações ao longo do tempo (Ahuja et al., 2012)

Considerando o contexto prévio, empírico e teórico, propõem-se o seguinte problema de pesquisa: Como é a dinâmica da agência e dos relacionamentos numa rede de sucesso composta por produtores rurais? A partir da questão de pesquisa, estabeleceu-se como objetivo analisar a trajetória de agência e de mudanças de relacionamentos entre os atores numa rede de produtores rurais que vem até o momento obtendo sucesso na sua organização.

Do ponto de vista acadêmico esta pesquisa quer contribuir para a compreensão do papel da agência individual e coletiva no processo de formação e evolução de uma rede de sucesso organizada por produtores rurais e nos consequentes padróes de relacionamentos entre os atores após a ocorrência destes tipos de eventos. Do ponto de vista empírico pretende-se contribuir para uma gestão consciente da agência individual e coletiva na criação de estruturas de redes que sustentem o sucesso da cooperação.

\section{Trajetória, agência e relacionamentos EM Redes}

As redes, sob o enfoque da Teoria de Eventos, são definidas por um conjunto de acontecimentos (eventos) interrelacionados entre si e conectados nas dimensões temporais - registros históricos do passado, acontecimentos em tempo real e perspectivas acerca do futuro. Os eventos são definidos através de percepções e interpretações dos atores, portanto, necessariamente, têm natureza relacional (Hedaa \& Törnroos, 2008). Conforme postulam, Halinen, Törnroos e Elo (2013), os eventos na pesquisa sobre uma determinada rede social correspondem aos pontos de verificação ou janelas para que se possa observar o desenvolvimento da rede, pois delimitam o intervalo de tempo a ser investigado. Um evento surge de atos únicos ou interligados que ocorrem em um determinado momento ou durante um período de tempo

Os eventos são considerados elementos socialmente construídos, sendo possível criar compreensão da verdade como "verdades locais" através da criação do conhecimento baseado em observações empíricas de uma comunidade, observações essas que podem ser limitadas pela subjetividade (Halinen, Törnroos \& Elo, 2013). Na pesquisa em rede isso significa que é necessário combinar vários pontos de vista dos atores sobre eventos-chave, coletar e cruzar dados de várias fontes para formar uma interpretação confiável do processo estudado. Assim, os eventos estão fundamentalmente ligados às percepções humanas do tempo e do processo. Logo, para a identificação dos eventos em um contexto organizacional, os gestores precisam se envolver em ações e pensamentos retrospectivos e prospectivos ao se referirem à suas experiências vividas e memórias para construirem uma interpretação da realidade (Halinen et al., 2013).

Os eventos, segundo Halinen, Törnroos e Elo (2013), podem surgir em diferentes níveis de uma rede. Eventos em nível da empresa referem-se, por exemplo, às mudanças na estrutura organizacional, de pessoal ou de estratégia da empresa. Eventos em nível de díade são exemplificados pelo fechamento de um contrato de longo prazo, aquisição ou substituição de um parceiro de negócios. Os eventos também podem advir de períodos de mudanças no amplo ambiente de negócios, por exemplo, uma recessão econômica ou uma transição tecnológica.

Ahuja et al.(2012) complementam a Teoria dos Eventos quando eles sugerem um conjunto de fatores que podem afetar a evolução de uma rede: agência, oportunidade, inércia e fatores exógenos e aleatórios, que, 
de acordo com suas definições, poderão desempenhar o papel de evento. Agência refere-se à motivação do ator focal e a sua capacidade de moldar as relações, criando vínculos positivos e dissolvendo os negativos, de modo a formar uma estrutura vantajosa. Oportunidade sugere que o comportamento de rede é conduzido pela lógica da confiança e da conveniência - através de laços formados entre indivíduos de um mesmo grupo social ou origem étnica - entre aqueles que possuem as mesmas metas e entre os que estão fisicamente ou virtualmente próximos. Inércia indica que, além dos laços na rede serem criados ou destruídos por agência e por oportunidade, podem também persistir pelas rotinas, normas e hábitos dos indivíduos no contexto de uma entidade. Fatores exógenos e aleatórios são aqueles que ifluenciam na estrurura e na trajetória da rede, porém não são previsíveis. Podem emergir, de maneira aleatória, tanto no ambiente interno quanto no ambiente externo da rede.

Em relação aos eventos com origem na agência e na oportunidade, o conceito de construtor de sistemas (system builders) permite compreender como estes fatores citados por Ahuja, et al.(2012) são articulados para que os eventos ocorram. Construtor de sistemas é definido como ator ou atores que são tecnicamente, financeiramente ou politicamente influentes e comprometidos por si só para iniciar a construção de um sistema com o objetivo de desenvolver ou implantar uma tecnologia (Jacobsson \& Johnson, 2000). O construtor de sistemas identifica problemas sistêmicos em uma rede e cria ações na busca de soluções. Estes problemas podem ser a criação de um mercado, experimentação e legitimação de uma tecnologia, coordenação de atores etc.

O construtor de sistemas geralmente inicia suas ações a partir dos recursos que ele controla e continuadamente amplia estas ações através do engajamento de outros atores (Musiolik et al.,2018). De acordo com a presença ou não de recursos necessários para resolver os problemas identificados e da concentração do recurso em único ator ou em mais de um, no caso destes recursos existirem internamente à rede, os construtores de sistemas podem ser de três tipos: one mode, partner mode e intermediary mode (Musiolik et al.,2018).

One mode: um ator individual identifica problemas e cria ou rearranja os atores do sistema para o desenvolvimento de uma estratégia para a rede, aplicando, se necessário, recursos controlados por si para resolver um problema identificado no sistema e gerar benefícios coletivos.

Partner mode: um conjunto de atores identificam problemas e criam ou rearranjam os demais atores do sistema para o desenvolvimento de uma estratégia para a rede, aplicando, se necessário, recursos controlados pelo grupo para resolver um problema identificado no sistema e gerar benefícios coletivos.

Intermediary mode: um conjunto de atores da rede inclui atores externos com recursos distintos ou capacidade de intermediar as soluções; se unem com o propósito de resolver um problema identificado no sistema e gerar benefícios coletivos.

Retornando a premissa de que as redes são compreendidas por um conjunto de eventos que ocorrem ao longo do seu processo de evolução, é de se esperar que estas redes se tornem cada vez mais horizontalizadas e menos hierarquizadas, onde todos os agentes envolvidos sejam beneficiados, principalmente em redes com sucesso (Feldhaus et al., 2012). Ahuja et al. (2012) indicam um conjunto de carcaterísticas dos atores e relacionamentos entre eles, carcaterísticas estas que permitem avaliar se estes eventos estão ou não contribuindo para o benefício dos atores pertencentes à rede.

Eventos podem favorecer para tornar os atores mais centrais. Os atores com maior grau de centralidade têm mais links e, consequentemente, eles podem acessar e obter mais do conjunto de recursos na rede (Ahuja et al., 2012). Além disso, se os eventos favorecem o menor distancimento entre dois atores de uma rede, é possível afirmar que a informação esteja se tornando mais democratizada, resultando em uma redução na vantagem informativa de um único ator (Ahuja et al., 2012). Os eventos podem favorecer a diminuição da ação descoordenada de subgrupos de atores dentro da rede, integrando e favorecendo a continuidade da rede (Ahuja et al., 2012). Além disso, se os eventos estão favorecendo a ligação entre todos os atores, isto indica uma consistência e proximidade entre eles (Granovetter, 1973), o que pode levar a uma crescente reunificação de 
ideias (Gulati, Sytch \& Tatarynowicz, 2012). Eventos podem favorecer a assortatividade (Ahuja et al., 2012), o que significa a tendência que as organizações altamente conectadas em uma rede - ou seja, que ocupam uma posição central - têm de formar laços adicionais com outras organizações também altamente conectadas (Gulati \& Gargiulo, 1999). Em contrapartida, as organizações com poucas conexões, localizadas na periferia da rede carecem de benefícios informativos e de reputação, situação que lhes restringe a possibilidade de caminhar em direção ao centro da rede (Corbo et al. 2016). A assortividade também pode ser associada a uma estrutura de núcleo/ periferia, onde os atores densamente conectados constituem o núcleo, enquanto que muitos outros (de baixo grau de conexões) constituem a periferia. $\mathrm{O}$ fenômeno do núcleo/periferia reconhece que em uma rede social existem atores periféricos que estão mais densamente interligados com atores do núcleo do que com os seus pares da periferia (Borgatti \& Everett, 1999).

\section{FIGURA 1}

Síntese teórica: eventos a partir da agência e mudanças de relacionamentos na rede
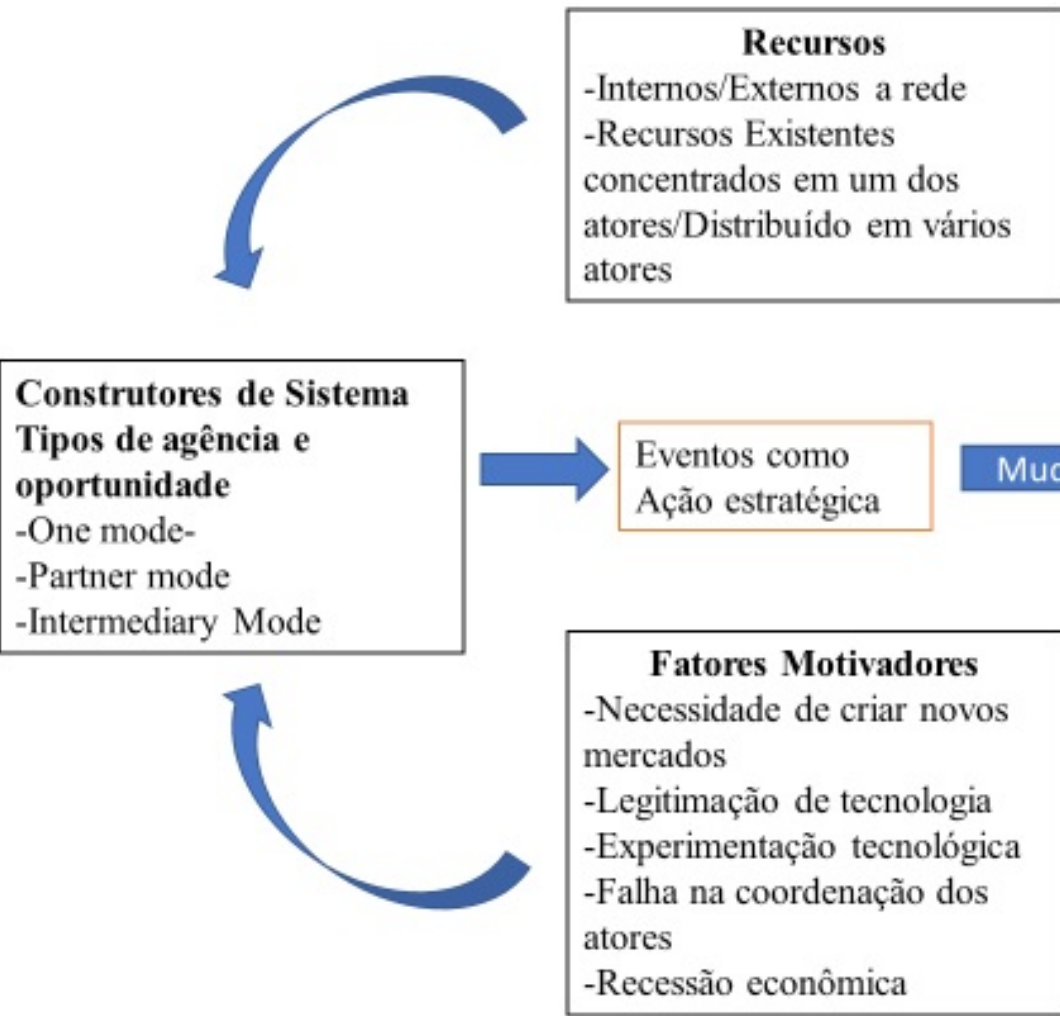

Musiolik et al. (2018); Halinen, Törnroos e Elo (2013); Ahuja, Soda e Zaheer (2012).

\section{Metodologia e PRocedimentos de PesQuisa}

Foi feito um estudo de caso exploratório e descritivo, sob uma estratégia de pesquisa qualitativa e quantitativa. A escolha da estratégia qualitativa deu-se por conta de que a pesquisa desenvolvida tem natureza histórica, visto que abordou a evolução do objeto de estudo desde a sua formação até o estágio atual (Yin, 2015). Por outro lado, também se adotou uma estratégia quantitativa de pesquisa, ou seja, a análise de redes sociais (SNA) que é um paradigma teórico e metodológico para analisar os sistemas sociais usando uma abordagem estrutural (Puffal, D \& Puffal, C., 2014).

A escolha da APROCCIMA como objeto de estudo foi em razão desta rede estar em atividade há 21 anos e se destacar entre outros CITES de composição e objetivos semelhantes. Os entrevistados foram escolhidos pela conveniência, isto é, pelas suas disponibilidades em responder às indagações. Vale ressaltar 
que os mesmos são sócios fundadores do CITE 120, ou seja, estiveram presentes desde a primeira reunião formal da rede, portanto são conhecedores de toda a sua história. A seguir, a figura 2 apresenta a identificação dos entrevistados e as datas da realização das entrevistas.

FIGURA 2

Quadro de identificação dos entrevistados

\begin{tabular}{|l|l|l|l|l|}
\hline $\begin{array}{l}\text { Código do } \\
\text { Respondente }\end{array}$ & $\begin{array}{l}\text { Posição no } \\
\text { CITE 120 }\end{array}$ & $\begin{array}{l}\text { Posição na } \\
\text { APROCCIMA }\end{array}$ & $\begin{array}{l}\text { Localização da } \\
\text { Propriedade } \\
\text { Rural }\end{array}$ & $\begin{array}{l}\text { Data das } \\
\text { Entrevistas }\end{array}$ \\
\hline CT1 & $\begin{array}{l}\text { Integrante } \\
\text { fundador e } \\
\text { atual } \\
\text { presidente }\end{array}$ & $\begin{array}{l}\text { Coordenador } \\
\text { da unidade } \\
\text { genética } \\
\text { bovina }\end{array}$ & $\begin{array}{l}\text { Município de } \\
\text { Vacaria, no Rio } \\
\text { Grande do Sul, } \\
\text { Brasil. }\end{array}$ & $\begin{array}{l}05 / 02 / 2018 \text { e } \\
09 / 07 / 2018\end{array}$ \\
\hline CT2 & $\begin{array}{l}\text { Integrante } \\
\text { fundador }\end{array}$ & $\begin{array}{l}\text { Coordenador } \\
\text { da unidade } \\
\text { agroturismo }\end{array}$ & $\begin{array}{l}\text { Município de } \\
\text { Ipê, no Rio } \\
\text { Grande do Sul, } \\
\text { Brasil. }\end{array}$ & $31 / 05 / 2018$ \\
\hline CT3 & $\begin{array}{l}\text { Integrante } \\
\text { fundador }\end{array}$ & $\begin{array}{l}\text { Coordenador } \\
\text { da unidade } \\
\text { carne bovina } \\
\text { e presidente }\end{array}$ & $\begin{array}{l}\text { Municipio de } \\
\text { Campestre da } \\
\text { Serra, no Rio } \\
\text { Grande do Sul, } \\
\text { Brasil. }\end{array}$ & $26 / 10 / 2017$ e \\
$27 / 2018$
\end{tabular}

Elaborado pelos autores (2018).

A coleta de dados foi feita através de três entrevistas semiestruturadas nos anos de 2017 e 2018 e de fontes documentais. O roteiro de entrevistas buscou responder as questões: Como surgiu e evoluiu a rede? Quais os eventos que condicionaram o desenvolvimento da rede? Além disso, foi perguntado: O que foi alterado nos relacionamentos entre os atores da rede após a ocorrência de cada evento? Quais os fatores que afetaram os eventos críticos citados? Estas questóes tiveram por objetivo elaborar uma sequência de eventos significativos que afetaram a evolução da rede.

Um evento crítico é aquele capaz de gerar alterações nos processos das redes, é o resultado de uma ação humana, voluntária ou involuntária, e de acontecimentos relativos aos fenômenos da natureza (Hedaa $\&$ Törnroos, 2008).

Para a validação da sequência de eventos, fatores motivadores, recursos e para a descrição das mudanças nos relacionamentos, foram feitas as análises das entrevistas, dos documentos e do histórico da rede disponível no site www.aproccima.com.br. Também foi feita a combinação das percepções dos entrevistados sobre os eventos mais significativos com relação às mudanças nos relacionamentos entre os atores durante o processo de evolução da rede pesquisada, para que assim se tivesse uma interpretação confiável acerca dos referidos eventos (Halinen et al.,2013).

Adicionalmente, foi aplicado um questionário fechado direcionado aos 32 produtores rurais e as 10 instituições de apoio com o objetivo de se mensurar os relacionamentos. Este questionário foi aplicado diretamente a 20 produtores, numa das reuniões da rede. O restante foi coletado por e-mail, o qual foi precedido por um contato telefônico. Antes da realização das respostas, os entrevistados foram orientados sobre a pesquisa e informados sobre as fases de evolução da rede e o significado de suas possíveis respostas. A questão que os respondentes precisaram responder foi: Classifique a importância do relacionamento de sua organização com as organizações listadas abaixo nos cinco períodos de evolução da rede elencados abaixo: (1) sem importância; (2) importante; (3) muito importante. A análise das mudanças estruturais na rede de relacionamentos foi realizada através dos indicadores oriundos da metodologia de Análise de Redes Sociais, 
com a utilização do software UCINET. As medidas estruturais que nortearam essa análise foram às propostas por Ahuja, Soda e Zaheer (2012), a saber: 1) centralidade, 2) conectividade na rede, 3 ) transitividade, 4) densidade, e 5) grau de assortatividade na rede.

O grau de centralidade reflete o número de contatos diretos ou adjacentes que um ator mantém em uma rede, uma vez que mede o seu nível de comunicação e torna possível avaliar a atividade local dos atores (Hanneman \& Riddle, 2005). A conectividade da rede é obtida pela medida de diâmetro entre os atores de uma rede. O diâmetro de uma rede é o caminho mais longo que conecta um par de nós (Wasserman $\&$ Faust, 1994). Transitividade é a tendência de formar laços mútuos entre atores e assim formando subgrupos (Ahuja et al., 2012). A densidade refere-se à proporção de laços que são realizados na rede em relação ao hipotético máximo possível. (Wasserman \& Faust, 1994). O grau de assortatividade da rede pode ser positivo ou negativo. A rede terá assortatividade positiva quando os nós mais centralizados tendem a se conectar com outros também altamente centralizados, enquanto que a dissortividade, ou assortatividade negativa, ocorre quando nós de alto nível de centralização tendem a se conectar a nós de baixa centralidade e vice-versa (Watts, 2004). A análise dos dados se baseou no esquema analítico proposto na Figura 1.

\section{Resultados}

Na subseção 3.1 faz se uma breve descrição da Aliança Mercadológica APROCCIMA. Na subseção 3.2 apresentam-se os resultados encontrados sobre o processo evolutivo desta rede, estruturada a partir da abordagem de eventos. A seguir, na subseção 3.3, tem-se a análise e discussão dos resultados orientada a partir da Figura 1.

\subsection{Aliança mercadológica APROCCIMA}

Aliança Mercadológica APROCCIMA é uma associação de produtores rurais, fundada em maio de 2006, com sede na cidade de Antonio Prado, Estado do Rio Grande do Sul (Brasil). Sua origem remonta ao ano de 1997, a partir da organização conjunta e voluntária de 16 produtores rurais que constituíram o CITE 120. Os CITEs - Clubes de Integração e Troca de Experiências - são grupos de produtores que se reúnem para discutir assuntos de interesse mútuo e desenvolver ações coletivas que venham a contribuir para a melhoria do desempenho de suas propriedades. O CITE 120, dos municípios da região dos Campos de Cima da Serra, apesar de ser conhecido como o CITE de Vacaria, congrega pecuaristas de vários municípios: Vacaria, Monte Alegre dos Campos, Bom Jesus, Campestre da Serra, Ipê, André da Rocha, Esmeralda, Caxias do Sul, São José dos Ausentes e Antônio Prado. Uma decisão importante foi a de padronizar os rebanhos bovinos através da opção pela raça britânica angus, em função de sua eficiência reprodutiva e precocidade - o que permite redução na idade de abate.

Esse arranjo deu origem à primeira rede de cooperação formada por produtores rurais, pessoas físicas, através do projeto Redes de Cooperação da Secretaria de Desenvolvimento e Assuntos Internacionais, do Governo do Estado do Rio Grande do Sul (Brasil) (Malafaia, 2009). A APROCCIMA é uma aliança mercadológica de iniciativa dos produtores rurais que definem os agentes responsáveis pelo processamento e comercialização da carne e estabelecem o sistema de produção, o padrão de qualidade e o preço de comercialização dos animais. O frigorífico e os varejistas que trabalham com a APROCCIMA se comprometem a cumprir os critérios definidos por esta associação de produtores. Essa situação difere do que, tradicionalmente, ocorre na cadeia da carne bovina, na qual o produtor se sujeita às exigências impostas pelos demais elos, particularmente pelos frigoríficos, com os quais se relaciona mais proximamente (Malafaia, 2009). 
De acordo com as características elencadas por Cunha, Passador e Passador (2010), a APROCCIMA é uma rede de formação espontânea, de aliança do tipo horizontal, com orientação do elo dada pelos produtores, de relações orientadas para fins comerciais e de institucionalização formal, mediante estatuto, regulamento interno e código de ética, o que a caracteriza como uma rede flexível (Casarotto Filho \& Pires, 1998). A rede foi formada pelas motivações de complementação de recursos e de atividades e também pelo fortalecimento do poder de barganha frente às instituições públicas e privadas. Ressalta-se a proximidade geográfica, cultural, cognitiva e social verificada entre os associados da APROCCIMA.

\subsection{A trajetória da APROCCIMA}

Vale lembrar que não se teve a pretensão de abordar a totalidade dos eventos que aconteceram durante toda a trajetória da rede, porém, serão abordados, apenas os mais significativos na percepção dos integrantes da rede. Pois, de acordo com Halinen, Törnroos e Elo (2013), o pesquisador deve buscar detectar os eventos significativos levando em conta a percepção dos atores com relação a tais eventos. Tendo em vista a rede focal em estudo, a APROCCIMA, desde a fundação do CITE 120 no ano de 1997 até o primeiro semestre de 2018, apresenta-se a seguir uma sequência de eventos significativos para o seu desenvolvimento.

\subsection{1 $1^{\circ}$ Evento: fundação do CITE 120}

Iniciamos a abordagem dos eventos a partir da fundação do CITE 120, que ocorreu no dia 22 de outubro de 1997, na sede do Sindicato Rural do município de Vacaria, no Estado do Rio Grande do Sul (Brasil). Nessa ocasião, reuniu-se um grupo de produtores rurais com o propósito de formar um CITE, o qual passaria a ser o CITE 120.

Em relação aos fatores que motivaram a fundação do CITE 120, percebe-se que um dos atores da atual rede tinha suas atividades profissionais fora da agricultura, entretanto ele teve a necessidade de voltar para ajudar os pais na condução da propriedade rural. Insatisfeito com o desempenho da propriedade, viu na política de Clubes de Integração a possiblidade de iniciar a resolver os seus próprios problemas identificados na propriedade. Então passou a atuar como um líder na formação da rede.

Acabei voltando para a propriedade de Vacaria para ajudar meus pais e trabalhando na propriedade eu vi que precisava voltar à ativa assim, não ficar só na propriedade, então buscar cursos e tudo (...) e me convidaram para ser secretário do Sindicato Rural de Vacaria e buscando essas informações que têm na volta, eu cheguei o que seria os clubes de integração e troca de experiências e aí eu tive a ideia de convidar um grupo de produtores, na época eram mais de vinte produtores e desses produtores, então se criou a ideia de fazer um grupo de CITE (CT1).

Considerando a existência de uma política de criação destes Clubes de Integração começou a atuar com diferentes instituições no processo de criação do CITE 120, a saber: Federação dos Centros de Integração e Troca de Experiências FEDERACITE, Sindicato Rural de Vacaria, Empresa de Assistência Técnica e Extensão Rural do Rio Grande do Sul, EMATER/RS, FARSUL, SENAR, SEBRAE e Universidade de Caxias do Sul (UCS):

A EMATER esteve presente desde o início, a FEDERACITE também, nós sempre tivemos o apoio também da Universidade de Caxias do Sul, da UCS (...) bem como sempre, desde o início, a FARSUL com a Casa Rural, o próprio SENAR, o próprio SEBRAE também depois que se somou, principalmente, quando foi criado o programa Juntos para Competir e o Sindicato Rural de Vacaria (CT1).

As trocas de experiências e os relacionamentos entre os participantes do CITE 120 começaram a se consolidar nas reuniões mensais, tendo sido a primeira no dia 06 de novembro de 1997. Essas reuniões foram realizadas tanto nas propriedades dos citeanos como em locais estrategicamente escolhidos para 
tratar de determinados objetivos, que basicamente eram: proporcionar maior qualificação e capacitação tecnológica aos componentes do grupo, aumentar a produtividade e a qualidade dos produtos agropecuários de forma sustentável e fomentar a liderança na comunidade com vistas à valorização do produtor rural (APROCCIMA, 2018).

Neste período, entre a fundação do CITE 120 em 1997 até o próximo evento de formação da Aliança Mercadológica da Carne em 2002, a rede foi caracterizada por um diâmetro de dois; densidade dos relacionamentos de 0,298; forte relação núcleo periferia (0,9074), com 10 atores participando do núcleo central; cliques (subgrupos) entre 4 atores (10 cliques) e 10 atores (14 cliques), sendo o clique médio de 7,17 e centralidade de 0,6847 .

\subsection{2 $2^{\circ}$ Evento: criação da Aliança Mercadológica da Carne}

Dando continuidade à sequência de eventos da APROCCIMA destaca-se, no ano de 2002, a criação da Aliança Mercadológica da Carne. A partir desse evento, a rede passou a dar foco no planejamento estratégico, que iria, além de promover o compartilhamento de conhecimentos e experiências entre seus integrantes, passar a trilhar o melhor posicionamento mercadológico para o seu principal produto, a carne. Para isso, a rede adotou modelo inspirado na Aliança Mercadológica de Guarapuava, a qual é liderada por produtores de bovinos de corte e está sediada no município de Guarapuava, no Estado do Paraná (Brasil): "Estivemos no Paraná visitando essa aliança mercadológica [Aliança Mercadológica de Guarapuava] para que pudéssemos nos organizar aqui como uma aliança mercadológica" (CT1).

A motivação para a criação da Aliança Mercadológica da Carne foi a percepção dos componentes da rede de que essa seria uma forma de agregar valor na cadeia, pois percebiam problemas no relacionamento com o elo frigorífico em relação a uma oferta de carne de qualidade em regime constante. Assim, ao analisar o conjunto de produtores que participaram da rede, constataram que estes teriam recursos suficientes para coordenar a solução deste problema: "o objetivo [da rede] de se produzir carne de qualidade e fornecimento constante. Após a definição das raças a serem trabalhadas e o tipo de terminação, passamos a exercitar a comercialização via aliança” (CT2).

Neste período, entre a formação da Aliança Mercadológica da Carne em 2002 até a conquista do título CITE do ano em 2003, a rede se caracterizou pela manutenção do diâmetro de dois atores; cresceu a densidade dos relacionamentos entre os atores para 0,333 ; manteve forte relação núcleo periferia $(0,9162)$, com 10 atores participando do núcleo central; os cliques cresceram variando entre 5 atores ( 12 cliques) e 11 atores (10 cliques), o que faz o clique médio aumentar para 7,68 e a centralidade diminui para 0,6647.

\subsubsection{Evento: conquista do título CITE do Ano}

A FEDERACITE, Federação dos Clubes de Integração e Troca de Experiências, que tem como objetivo promover a consolidação e a prosperidade dos CITEs, instituiu um prêmio anual de reconhecimento para aqueles que tenham se destacado em quesitos como - aumento da produtividade, adoção de práticas agropecuárias sustentáveis, inovação nos sistemas de cultivo e de criação, e, sobretudo, na colocação em prática dos princípios da colaboração entre os próprios integrantes de cada CITE e destes com a comunidade envolvida nas atividades rurais (Federação dos Clubes de Integração e Troca de Experiências [FEDERACITE], 2016).

Interessados em ganhar legitimidade da FEDERACITE e com isso do mercado, os produtores rurais componentes da rede se motivaram a participar do concurso. Com a conquista do prêmio ficou legitimado que a FEDERACITE reconheceu que o grupo de produtores vem desempenhando sua missão. Um dos 
produtores mencionou que "essa conquista mostrou a maturidade do grupo e despertou a vontade de ampliar suas ações" (CT2).

A partir daí os produtores da rede, motivados pelo reconhecimento obtido no ano de 2003, seguem uma nova caminhada - restabelecem convênio com a EMATER e passam a ter o apoio da Embrapa Pecuária Sul e da Universidade de Caxias do Sul, UCS. Adicionalmente, aderem ao programa Juntos para Competir do Serviço Brasileiro de Apoio às Micro e Pequenas Empresas, SEBRAE e conquistam mais um produtor rural para o seu quadro de sócios, adquirem novos equipamentos agrícolas para o incremento das lavouras e também promovem o fortalecimento da bovinocultura de corte e de leite (FEDERACITE, 2018)

Neste período, entre a conquista do título CITE do ANO até a formação da Associação dos Produtores Rurais dos Campos de Cima da Serra - APROCCIMA (próximo evento), a rede se caracterizou pela manutenção do diâmetro de dois atores; cresceu a densidade dos relacionamentos entre os atores para 0,355; manteve forte relação núcleo periferia $(0,9306)$, com 10 atores participando do núcleo central; a quantidade de cliques menores (de 5 atores) diminuíram para 9 subgrupos) e os cliques maiores se mantiveram (cliques com 11 atores e 10 subgrupos), o que faz o novamente o clique médio aumentar para 8,31. A centralidade também diminui para 0,6401 .

\subsection{4 $4^{\circ}$ Evento: formação da Associação dos Produtores Rurais dos Campos de Cima da Serra - APROCCIMA}

Na sequência da trajetória da rede, ocorreu a formação da Associação dos Produtores Rurais dos Campos de Cima da Serra - APROCCIMA (APROCCIMA, 2018). A criação da APROCCIMA foi motivada pela iniciativa dos produtores rurais da rede, que perceberam que uma vez tendo a produção de bovinos qualificada poderiam agregar as margens de lucro do elo frigorífico. Então atuaram conjuntamente na contratação de um frigorífico, localizado no município de Farroupilha, no Estado do Rio Grande do Sul. Para viabilizar a contratação do frigorífico, a APROCCIMA passou a definir como um compromisso dos membros a entrega semanal de uma quantidade pré-determinada de bovinos para serem abatidos e processados no frigorífico contratado. Após o abate, as carcaças passaram a ser direcionadas ao varejo escolhido pela rede. A APROCCIMA estabeleceu parceria com 5 empresas varejistas - uma no município de Garibaldi, outra no município de Bento Gonçalves, e três no município de Antônio Prado, todas no Estado do Rio grande do Sul.

Além disso, passaram a atuar conjuntamente em remates e feiras de gado geral e de reprodutores; isto é, os remates dos touros da APROCCIMA. Verificam-se ainda outras formas de relacionamento, como a relação com outros grupos de produtores e a prestação de serviços entre os membros da rede, em atividades como a prestação do serviço de carregamento dos animais das propriedades rurais até o frigorífico: "Também nós fizemos dois remates de touros, touros da APROCCIMA, de quem produzia genética na APROCCIMA. Fizemos também remate de gado geral do grupo, o grupo várias vezes participou em feiras, principalmente, por exemplo, em Esteio" (CT1).

Da formação da APROCCIMA em 2006 até a adesão ao Programa de Boas Práticas Agropecuárias em 2009, a rede se caracterizou pela manutenção do diâmetro em dois atores; cresceu a densidade dos relacionamentos entre os atores para 0,508 ; reduziu a relação núcleo periferia $(0,8774)$, com 14 atores participando do núcleo central; a quantidade de cliques menores (de 5 atores) diminuiu para 1 subgrupo, e os cliques maiores aumentaram e passaram a ser de 14 membros ( 5 subgrupos), o que fez novamente o clique médio aumentar para 10,27. A centralidade decresce para 0,5816. 


\title{
3.2.5 $5^{\circ}$ Evento: adesão ao Programa Boas Práticas Agropecuárias
}

O Programa\#Boas Práticas Agropecuárias, o BPA, é um conjunto de normas e de procedimentos a serem observados pelos produtores rurais, que, além de tornar os sistemas de produção mais rentáveis e competitivos, garantem, também, a oferta de alimentos seguros. O BPA capacita as organizações agropecuárias para que trabalhem de acordo com os princípios da responsabilidade social e ambiental. A partir de 2009, o programa foi desenvolvido no Estado do Rio Grande do Sul pela Empresa Brasileira de Pesquisa Agropecuária Unidade Sul, EMBRAPA em parceria com a EMATER/RS.

Em 2009, a APROCCIMA faz adesão ao programa. Com relação à motivação dos produtores para aderirem ao programa BPA, verificou-se a percepção dos membros da rede de que era necessário se antecipar às necessidades dos clientes através de uma certificação.

\begin{abstract}
Nós tivemos essa ideia de buscar [a certificação em BPA], porque já existia em outros estados brasileiros, essa ideia de cuidar bem dos animais do meio ambiente e tudo. E aí veio o pessoal da EMBRAPA, juntamente com o pessoal da EMATER e eles foram então que fizeram todas as reuniões conosco, tivemos quatro verificações nas propriedades, no caso auditorias que culminaram então, depois de quase cinco anos de trabalho, na certificação de sete das nossas propriedades, nós éramos doze e certificamos sete propriedades. Atualmente, quem está certificando junto com a EMBRAPA é o SENAR, Serviço Nacional de Aprendizagem Rural (...), então é tentar um resultado positivo nesses cento e vinte e sete itens de verificação, porque nós estamos nos antecipando àquilo que o cliente poderá exigir lá na frente - se nós cuidamos bem do meio ambiente, se nós cuidamos bem dos animais. Inclusive nós aqui em casa, terminamos há pouco tempo, uma construção de instalações novas visando o bem-estar animal (...). Por exemplo, o tratamento com os funcionários, se eles têm carteira assinada, evitar o trabalho escravo, todas essas questões a gente procura fazer de acordo (...). Esse programa, ele é de adesão voluntária, tudo o que nós fizemos aqui, nós não fomos obrigados, foi uma decisão nossa sim de fazer, de conquistar a certificação (CT2).
\end{abstract}

Neste período, entre a adesão ao Programa de Boas Práticas Agropecuárias em 2009 até a aquisição de loja própria para as carnes da APROCCIMA em 2018, a rede se caracterizou pela manutenção do diâmetro de dois atores; cresceu a densidade dos relacionamentos entre os atores para 0,771; reduziu a relação núcleo periferia $(0,8114)$ e nesta fase com 16 atores participando do núcleo central; os cliques menores aumentaram para 8 atores ( 6 subgrupos) os cliques maiores aumentaram e passaram a ter 17 membros (12 subgrupos)e novamente o clique médio aumentou para 14,12. A centralidade novamente diminui para 0,4399.

\subsection{6 $6^{\circ}$ Evento: abertura da loja de carnes Estância do Assador}

O mais novo empreendimento da APROCCIMA está em fase de conclusão. Trata-se da aquisição de um ponto de varejo para as carnes provenientes das propriedades associadas. A obra está em fase de acabamento e os equipamentos estão sendo instalados, os associados pretendem inaugurá-la em agosto de 2018. A loja está localizada no município de Caxias do Sul, no Estado do Rio Grande do Sul (Brasil). A empresa cujo nome fantasia é Estância do Assador. No conjunto de associados existe um grupo de quatro pessoas que possuem 50 cotas cada uma, seguidas por uma quarta que possui 40 cotas e por uma quinta que possui 30, tudo isso em relação ao um total de 304 cotas. O restante das cotas está distribuído de maneira equilibrada entre os outros oito sócios. A loja será gerenciada por um dos membros da rede.

Com relação à motivação dos produtores de carnes da APROCCIMA para estabelecerem uma unidade de varejo própria, destaca-se a intenção deles de abrangerem todos os elos da cadeia, agregarem à margem de lucro deste elo da cadeia e controlarem a atividade de comercialização.

Não temos problemas com os consumidores finais, eles compram a nossa carne, compram e aprovam, na verdade, compram aprovam e pagam (...) então sempre quisemos estar mais próximos deles, quanto menor a interferência dos intermediários, melhor. As lojas querem o filé do filé, mas querem isso, querem escolher, ainda querem colocar os preços, digo, impor preços não compatíveis, mais baixos no caso, com o tipo de carne que exigem. Para a nossa loja irão as carnes mais especiais, para as 
demais, que também vendem para nós, essas sim, também vão receber uma boa carne, mas não tão especial, porque se querem o melhor, terão que pagar o que vamos pedir, e não o que elas querem nos impor (CT1).

A instituição de apoio presente no processo de implantação do novo negócio, a loja de carnes, é notadamente o SEBRAE, além dos próprios membros da rede. Essa instituição apoiou desde a fase dos estudos de viabilidade econômica, treinamento de pessoal, layout e decoração:

O principal parceiro hoje e que já é há bastante tempo é o SEBRAE. Via SEBRAE nós fomos buscar empresas especializadas, nós temos um técnico, ele é administrador, o nome dele é Lucas Cézar e ele está fazendo toda parte de estruturamento do negócio. Também via SEBRAE foi contratada a pessoa para fazer o treinamento dos funcionários, até a implantação, o pessoal de TI, tudo via SEBRAE. A parte de decoração, folders promocionais e até os modelos dos uniformes dos funcionários, tudo foi contratado através do SEBRAE, base principal era e continua sendo o SEBRAE (CT1).

Para finalizar esta subseção elaborou-se uma síntese dos resultados encontrados na descrição do processo evolutivo da APROCCIMA (Figuras 3 e 4).

FIGURA 3

Quadro síntese dos fatores motivadores, recursos, agência e eventos na trajetória da APROCCIMA

\begin{tabular}{|c|c|c|c|c|c|c|}
\hline Resultados & $1^{\circ}$ evento & $2^{\circ}$ evento & $3^{\circ}$ evento & $4^{\circ}$ evento & $5^{\circ}$ evento & $6^{\circ}$ evento \\
\hline \multirow[b]{2}{*}{$\begin{array}{l}\text { Fatores } \\
\text { motivadores }\end{array}$} & $\begin{array}{l}\text { Internoe } \\
\text { individual }\end{array}$ & $\begin{array}{l}\text { Internoe } \\
\text { coletivo }\end{array}$ & $\begin{array}{l}\text { Internoe } \\
\text { coletivo }\end{array}$ & $\begin{array}{l}\text { Internoe } \\
\text { coletivo }\end{array}$ & $\begin{array}{l}\text { Externoe } \\
\text { coletivo }\end{array}$ & $\begin{array}{l}\text { Internoe } \\
\text { coletivo }\end{array}$ \\
\hline & $\begin{array}{l}\text { Baixo } \\
\text { desempenho } \\
\text { econômico } \\
\text { individual } \\
\text { da } \\
\text { propriedade } \\
\text { agrícola }\end{array}$ & $\begin{array}{l}\text { Problemas } \\
\text { de qualidade } \\
\text { no } \\
\text { fornecimento } \\
\text { aos } \\
\text { frigoríficos }\end{array}$ & $\begin{array}{l}\text { Oportunidade } \\
\text { de legitimar } \\
\text { a rede }\end{array}$ & $\begin{array}{l}\text { Oportunidade } \\
\text { de melhorar } \\
\text { o } \\
\text { desempenho } \\
\text { econômico } \\
\text { dos } \\
\text { membros da } \\
\text { rede }\end{array}$ & $\begin{array}{l}\text { Ameaça de } \\
\text { exigência por } \\
\text { parte do } \\
\text { consumir por } \\
\text { garantias em } \\
\text { aspectos de } \\
\text { sustentabilidade } \\
\text { nos processos } \\
\text { produtivos }\end{array}$ & $\begin{array}{l}\text { Oportunidade } \\
\text { de melhorar } \\
\text { o } \\
\text { desempenho } \\
\text { econômico } \\
\text { dos } \\
\text { membros da } \\
\text { rede }\end{array}$ \\
\hline Recursos & $\begin{array}{l}\text { Internos } \\
\text { distribuidos } \\
+ \text { Externos }\end{array}$ & $\begin{array}{l}\text { Internos } \\
\text { distribuidos }\end{array}$ & $\begin{array}{l}\text { Internos } \\
\text { distribuidos }\end{array}$ & $\begin{array}{l}\text { Internos } \\
\text { distribuidos }\end{array}$ & $\begin{array}{l}\text { Internos } \\
\text { distribuidos }+ \\
\text { Externos }\end{array}$ & $\begin{array}{l}\text { Internos } \\
\text { distribuidos }\end{array}$ \\
\hline $\begin{array}{l}\text { Tipo de } \\
\text { agência }\end{array}$ & $\begin{array}{l}\text { Intermediary } \\
\text { Mode }\end{array}$ & Partner mode & Partner mode & Partner Mode & $\begin{array}{l}\text { Intermediary } \\
\text { Mode }\end{array}$ & Partner mode \\
\hline Evento & $\begin{array}{l}\text { Fundação } \\
\text { do CITE } 120\end{array}$ & $\begin{array}{l}\text { Criação da } \\
\text { Aliança } \\
\text { mercadológica }\end{array}$ & $\begin{array}{l}\text { Conquista do } \\
\text { título CITE } \\
\text { do Ano }\end{array}$ & $\begin{array}{l}\text { Fundação da } \\
\text { APROCCIMA }\end{array}$ & $\begin{array}{l}\text { Adesão ao } \\
\text { Programa de } \\
\text { Boas Práticas } \\
\text { Agropecuárias }\end{array}$ & $\begin{array}{l}\text { Abertura da } \\
\text { Loja Estância } \\
\text { do Assador }\end{array}$ \\
\hline
\end{tabular}

Elaborado pelos autores (2018). 
FIGURA 4

Quadro síntese dos padrões de relacionamentos na trajetória da APROCCIMA

\begin{tabular}{|c|c|c|c|c|c|}
\hline \multicolumn{6}{|c|}{ Mudanças nos Relacionamentos } \\
\hline PERÍODO & Entre $1^{\circ}$ e $2^{\circ}$ evento & Entre $2^{\circ}$ e $3^{\circ}$ evento & Entre $3^{\circ}$ e $4^{\circ}$ evento & Entre $4^{\circ}$ e $5^{\circ}$ evento & Entre $5^{\circ}$ e $6^{\circ}$ evento \\
\hline Diâmetro & 2 & 2 & 2 & 2 & 2 \\
\hline Densidade & 0,298 & 0,333 & 0,355 & 0,508 & 0,771 \\
\hline Cliques & 7,17 & 7,68 & 8,31 & 10,27 & 14,12 \\
\hline $\begin{array}{l}\text { Assortatividade - correlação } \\
\text { núcleo-periferia }\end{array}$ & 0,9074 & 0,9162 & 0,9306 & 0,8774 & 0,8114 \\
\hline $\begin{array}{l}\text { Assortatividade }-n^{\circ} \text { atores } \\
\text { centrais }\end{array}$ & 10 & 10 & 10 & 14 & 16 \\
\hline Centralidade & 0,6847 & 0,6647 & 0,6401 & 0,5816 & 0,4399 \\
\hline
\end{tabular}

Elaborado pelos autores (2018).

As figuras 5, 6, 7, 8, 9 e 10 representam graficamente os cinco períodos da evolução da rede.

\subsection{Análise e discussão}

Uma análise comparativa entre o framework analítico teórico (Figura 1) e os resultados empíricos descritos na seção 3.2 pode ser evidenciada no framework teórico-empírico (Figura 5).

\section{FIGURA 5}

Framework teórico-empírico de evolução das redes

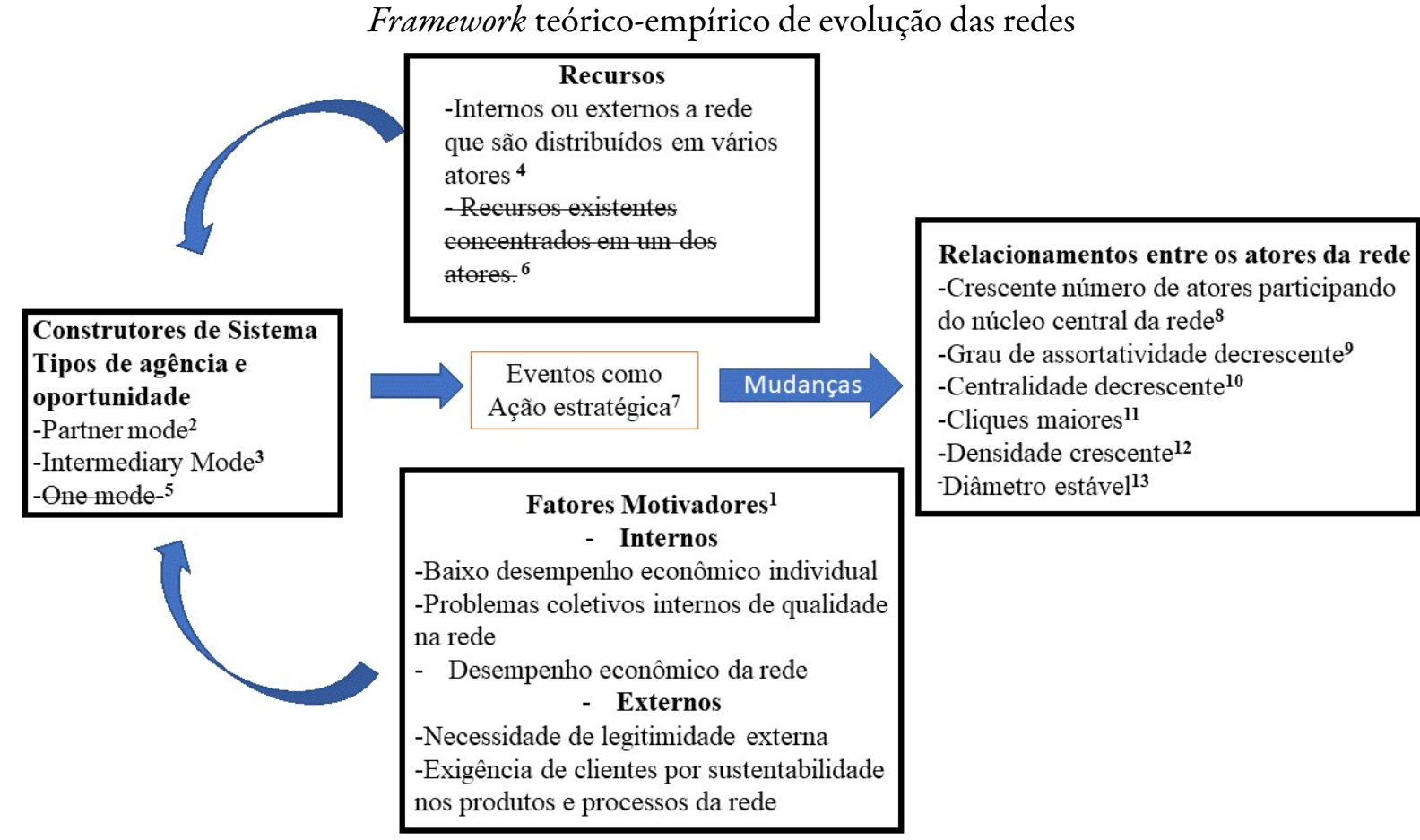

Elaborado pelos autores (2019). 


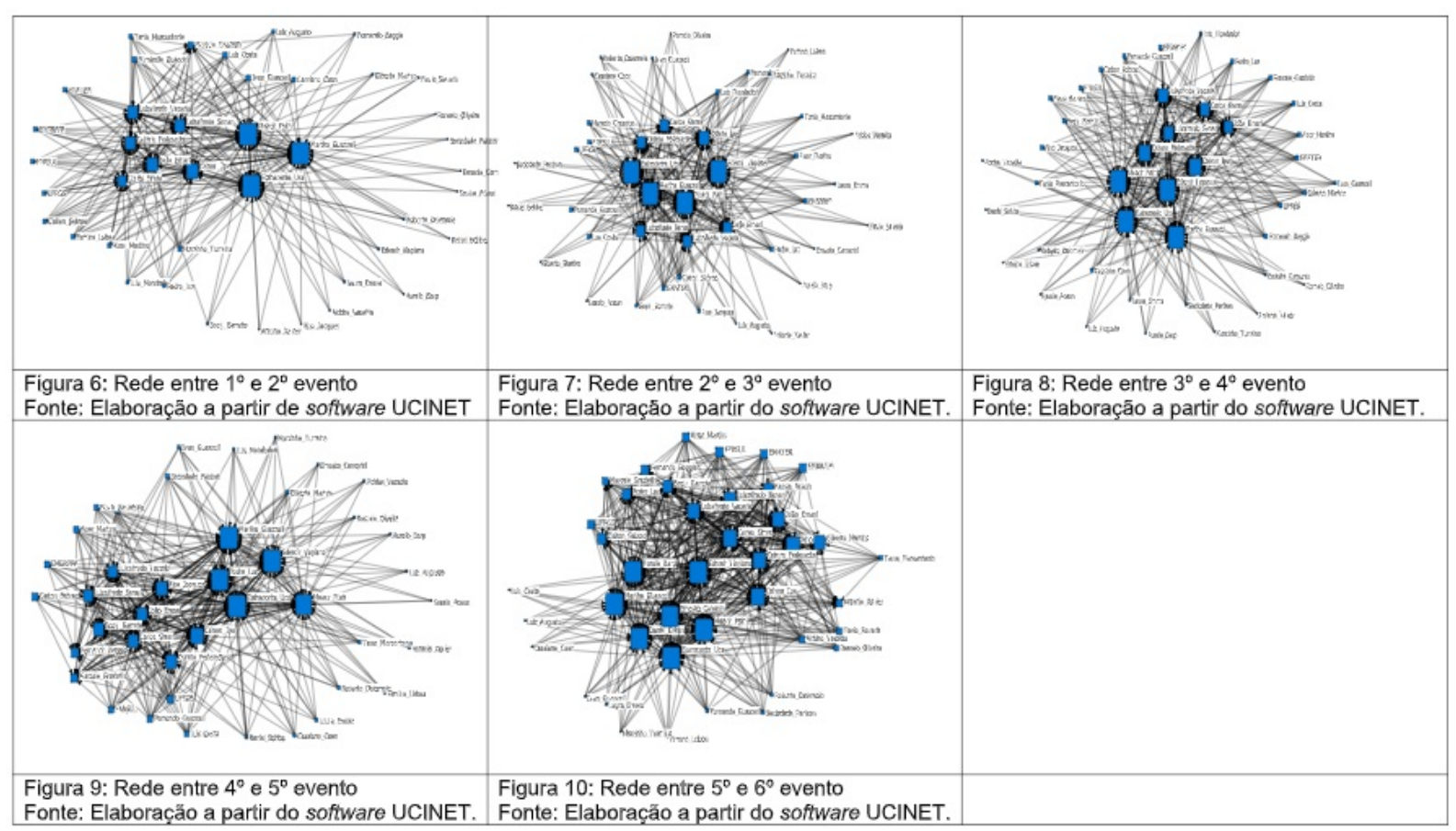

As mudanças nas estruturas das redes interorganizacionais têm sido tipicamente associadas a fatores motivadores externos a elas (Corbo et al., 2016; Dagnino et al., 2016), o que foi observado pela percepção de que os clientes estão desejando mais sustentabilidade nos produtos e processos desenvolvidos na rede. Entretanto, os resultados desta pesquisa comprovam que os fatores internos (Ahuja et al., 2012), tanto individuais, como coletivos, também podem provocar mudanças estruturais nas redes. Motivaram mudanças na rede, o baixo desempenho econômico individual, o que motivou a própria criação da rede, além de problemas coletivos de qualidade, sustentabilidade e desempenho econômico da rede. ${ }^{1}$

Uma vez que os fatores motivadores tenham sido reconhecidos pelos atores da rede, foi observado agência de dois tipos: Partner mode e Intermediary mode. A agência dos tipos Partner mode Intermediary mode foram decorrentes da percepção de que havia necessidade de recursos compartilhados internos ou externos à rede para a resolução dos problemas (Musiolik et al., 2018).

O tipo de agência One mode não foi observado, o que pode ser associado ao fato da rede ser constituída por agricultores de pequeno e médio recursos, ou seja, nenhum deles teria recursos suficientes para implementar uma estratégia com os seus recursos próprios (Musiolik et al.,2018).

Partindo da premissa de que as redes flexíveis implicam em relação horizontalizada entre todos os atores envolvidos (Casarotto Filho \& Pires, 1998; Feldhaus et al., 2012), constatou-se na APROCCIMA diferentes graus de horizontalidade nas relações ao longo do tempo e os eventos contribuíram para aprimorar a rede em quatro das cinco características de relacionamentos propostas por Ahuja et al. (2012).

A presença da estrutura core-periferia (Watts, 2004) indicou a presença de dois tipos atores: centrais e periféricos na estrutura da rede. Foi crescente o número de atores do núcleo central, sendo que estes atores mantiveram-se fortemente relacionados entre si e a uma periferia de atores menos integrados entre si, porém bastante integrados ao núcleo. Atores mais centrais podem se beneficiar desta posição pela maior disponibilidade de informação. Apesar deste resultado indicar um grau de verticalidade nas relações, constatou-se que após os eventos houve um crescimento do número de atores atuando no núcleo da rede $\mathrm{e}$ uma redução da correlação, o que indica que os eventos estão contribuindo para a maior inserção de todos os atores na rede, o que se refletiu no decréscimo do grau de centralização da rede ao longo do tempo. 
O crescimento do tamanho dos cliques sugere também que a rede está se integrando cada vez mais ao longo do tempo, evitando assim que a rede corra o risco de se diferenciar em uma variedade de sub-redes ou comunidades distintas, o que pode levar ao fracasso da rede pela extinção ou divisão (Ahuja et al., 2012).

A densidade crescente indica que os atores estão cada vez mais se relacionando uns com os outros, e tornando a rede mais efetiva no sentido de realizar seu potencial através do preenchimento de todos os laços possíveis entre os atores (Ahuja, et al. 2012; Scoponi, Pacheco Dias, Pesce, Schmidt, \& Gzain, 2016). Por último, não se constatou diferenças no diâmetro, ou seja, caminho mais longo que conecta um par de atores, o que provavelmente se explica pelo número já pequeno do diâmetro de 2 .

\section{CONSIDERAÇÕES FINAIS}

Retoma-se o objetivo geral deste trabalho de analisar a trajetória de agência e de mudanças de relacionamentos entre os atores numa rede produtores rurais que vem até o momento obtendo sucesso na sua organização. Constatou-se que a percepção de problemas associados a fatores internos e externos à rede, em associação com a análise da disponibilidade de recursos distribuídos entre os atores internos e externos, pode provocar uma ação de agência envolvendo somente atores internos ou com atores externos à rede e, como consequência, criar eventos na rede. Os eventos podem criar mudanças estruturais no relacionamento entre os atores da rede e, assim, favorecer a formação de uma estrutura de relacionamento adequada à continuidade da rede.

Considerando o sucesso da APROCCIMA, pode-se inferir que os eventos precisariam contribuir para uma melhora na estrutura de relacionamentos das redes em pelo menos quatro das cinco características de avaliação dos relacionamentos. São elas: centralidade decrescente, cliques maiores, densidade crescente, grau de assortatividade decrescente e crescente número de atores participando do núcleo central da rede. Apesar de o diâmetro ter se mantido estável, este já se apresentou deste o início da rede como um indicador de muita proximidade entre os atores.

Como contribuição gerencial, acredita-se que esta pesquisa tenha utilidade às redes rurais, servindo, por exemplo, para que possam analisar como os eventos da rede podem melhor integrar os membros. Adicionalmente, espera-se que este trabalho possa servir de estímulo para que outras redes de produtores rurais, especialmente os CITEs, ainda incipientes, se organizem e tenham uma trajetória significativa como a do CITE 120.

Para pesquisas futuras em redes interorganizacionais, sugere-se que sejam levados em conta, eventos de natureza negativa, gerados por fatores internos e externos à rede, e como estes impactaram nas características de relacionamentos. Além disso, sugerem-se estudos que indiquem quais e como os processos interorganizacionais foram realizados nas redes para viabilizar os efeitos positivos dos eventos.

\section{REFERÊNCIAS}

Agostino, D., Arnaboldi, M., \& Dal Molin, M. (2017). Critical crossroads to explain network change: evidence from a goal-directed network. International Journal of Public Sector Management. Bingley, 30(3), 255-269

Agranoff, R., \& Mcguire, M. (2001). Big Questions in public network management research. Journal of public administration research and theory. Oxford, 11(3), 295-326.

Ahuja, G. (2000). Collaboration networks, structural holes, and innovation: a longitudinal study. Administrative science quarterly. New York, 45(3), 425-455.

Ahuja, G., Soda, G., \& Zaheer, A. (2012). The genesis and dynamics of organizational networks. Organization Science, Catonsville, 23(2), 434-448.

APROCCIMA. (2018). Unidades de negócio: carne bovina. Recuperado em 5, julho, 2018 de: http://www.aprocci ma.com.br/unidades.php?pagina $=2$. 
Marcelo Fernandes Pacheco Dias, et al. Trajetória de redes: uma análise da dinâmica da agência e ...

Barcellos, P. F. P., Barella, R. M. C., Peretti, J.L. G., \& Galleli, A. (2015). Insucesso em redes de cooperação: estudo multicascos. Revista Portuguesa e Brasileira de Gestão. Lisboa, 11(4), 49-57.

Bizzi, L., \& Langley A. (2012). Studying processes in and around networks. Industrial Marketing Management, 41, 224-234.

Borgatti, S. P., \& Everett, M. G. (1999). Models of core/periphery structures. Social Networks, 21(4), 375-395.

Braga, M. J. (2010). Redes, alianças estratégicas e intercooperação: o caso da cadeia produtiva de carne bovina. Revista Brasileira de Zootecnia.Viçosa, 39(Supl. Spe), 11-16

Capaldo, A. (2007). Network structure and innovation: the leveraging of a dual network as a distinctive relational capability. Strategic Management Journal, 28(6), 585-608.

Casarotto FILHO, N., \& PIRES, L. H. (1998). Redes de pequenas e médias empresas e desenvolvimento local. São Paulo: Atlas.

Corbo, L., Corrado, R., \& Ferriani, S. (2016) A new order of things: network mechanisms of field evolution in the aftermath of an exogenous shock. Organization Studies, 37(3), 323-348.

Cropper, S., Ebers, M., Huxham, C., \& Ring, P. S. Handbook de relaçóes interorganizacionais da Oxford. Porto Alegre: Bookman, 2014.

Cunha, J. A. C., Passador, J. L., \& Passador, C. S. (2011). Recomendações e apontamentos para categorizações em pesquisas sobre redes interorganizacionais. Cadernos EBAPE.BR, Rio de Janeiro, 9(Edição Especial), 505-529.

Dagnino, G. B., Levanti, G., \& Destri, A. M. L. (2016). Structural dynamics and intentional governance in strategic interorganizational network evolution: a multilevel approach. Organization Studies, 37(3), 349-373.

Escosteguy A. (2016). Atualmente, a demanda por alimentos orgânicos é maior do que a oferta e, por isso, o preço está alto e muito favorável para quem produz. Revista do Conselho Regional de Medicina Veterinária, Porto Alegre, 21(88).

FEDERAÇÃO DOS CLUBES DE INTEGRAÇÃO E TROCA DE EXPERIÊNCIAS. [FEDERACITE] (2018). CITE 120: Vacaria. Recuperado em 28, junho, 2018 de: http://www.federacite.com.br/cites_int.php?id=21.

Freeman, L. C. (1979). Centrality in social networks conceptual clarification. Social Networks, 1(3), 215-239.

Feldhaus, D. C., Pereira, M. F., \& Morais Neto, S. (2012). Gestão estratégica em redes: desenvolvimento e aplicação de um modelo na Brasil Júnior. Revista de Gestão e Projetos, 3(3), 136-155

Ferreira, G. C., \& Padula, A. D. (2002). Gerenciamento de cadeias de suprimento: novas formas de organização na cadeia da carne bovina do Rio Grande do Sul. Revista de Administração Contemporânea, São Paulo, 6(2), 167-184.

Granovetter, M. (1973). The strength of weak ties. American jornal of sociology, 1360-1380.

Gulati, R., \& Gargiulo, M. (1999). Where do interorganizational networks come from? American journal of sociology, Chicago, $104(5), 1439-1493$.

Gulati, R., Sytch, M., \& Tatarynowicz, A. (2012). The rise and fall of small worlds: exploring the dynamics of social structure. Organization Science, 23(2), 449-471.

Halinen, A., \& Törnroos, J. A. (2005). Using case methods in the study of contemporary business networks. Journal of Business Research, 58(9), 1285-1297.

Halinen, A., Törnroos, J. A., \& Elo M. (2013). An event-based approach to study business network dynamics. Industrial Marketing Management, 42(8), 1213-1222.

Hanneman, R. A., \& Riddle, M. (2005). Introduction to social network methods. Riverside: Riversite: University of California.

Hedaa, L., \& Tornroos, J.A. (2008). Understanding event-based business networks. Time \& Society, Sage, 17(2-3), 319-348.

Jackson, M. O. (2010). Social and economic networks. Princeton: Princeton university press.

Jacobsson, S, \& Johnson, A. (2000). The diffusion of renewable energy technology: and key issues for research. Energy policy, 28(9), 625-640. 
Malafaia, G. C., Maciel, A. C., Camargo, M. E. (2009). Attitude de coordenação de produtores rurais na cadeia de carne bovina: o caso do cite 120. Organizações rurais \& agroindustriais. Lavras, 11(3), 393-406.

Musiolik, J., Markard, J., Hekkert, M., \& Furrer, B. (no prelo). Creating innovation systems: how resource constellations affect the strategies of system builders. Technological Forecasting and Social Change. Recuperado em: 28, fevereiro, 2020 de: https://doi.org/10.1016/j.techfore.2018.02.002.

Oliveira, T., Gianezini, M., Peripoli, V., \& Barcellos, J. O. J. (2015). Alianças mercadológicas e estratégicas e elementos de diferenciação na cadeia de carne bovina no Brasil. Ibero-American Journal os Strategic Management (IJSM), North America, 14.

Pereira, B. A. D., Venturini, J. C., Wegner, D., \& Braga, A. L. (2010). Desistência da cooperação e encerramento de redes interoriganizacionais: em que momento essas abordagens se encontram? INMR-Innovation \& Management Review, 7(1), 62-83.

Puffal, D. D. P., \& Puffal, C. W. (2014). A evolução do campo de estudos de redes interorganizacionais: uma análise de publicações internacionais das relações entre empresas. Revista Brasileira de Gestão e Inovação, 1(3), 63-86.

Scoponi, L., Pacheco Dias, M. F., Pesce, G., Schmidt, M. A., \& Gzain, M. (2016). Cooperación Académica em Latino américa para la Innovación em los Agronegocios. Journal of Technology Management \& Innovation, 11(2), 111-120.

Wasserman, S., \& Faust K. (1984). Socialnetwork analysis: methods and applications. New York: Cambridge University Press.

Watts, D. J. (2004). The" new" science of networks. Annual review of sociology, 30, 243-270.

Watts, D. J., Strogatz, S. H. (1998). Collective dynamics of small-world networks. Nature, 393(6684), 440-442.

Wegner, D., \& Padula, A. D. (2010). Governance and management of horizontal business networks: an analysis of retail networks in Germany. International Journal of Business and Management, 5(12), 74.

Yin, Robert K. (2015). Estudo de caso: planejamento e métodos. Porto Alegre: Bookman, 2015.

\section{Notas}

1 Os números sobrescritos indicam a parte da Figura 10 no qual está sendo discutido.

\section{BY-NC-SA}

